\title{
RESUMO
}

\section{GÊNERO E DIREITO: DEBATES TEÓRICOS E POSSIBILIDADES EMPÍRICAS}

\author{
GENDER AND LAW: \\ THEORETICAL DISCUSSION AND EMPIRICAL POSSIBILITIES
}

\section{GÉNERO Y DERECHO: \\ DEBATES TEÓRICOS Y POSIBILIDADES EMPIIRICAS}

As propostas epistemológicas dos estudos feministas e de gênero pensam uma nova perspectiva para os estudos das ciências, ao criticarem a suposta neutralidade, universalidade e objetividade da ciência tradicional. 0 direito como uma tecnologia que visa regrar as relações sociais não é neutro ou imparcial, pois a partir das lentes dos estudos de gênero podemos perceber uma moral generificada que valora e posiciona diferentemente homens e mulheres na sociedade.

\section{PALAVRAS-CHAVE}

Gênero e Direito. Estudos de Gênero e Feministas. Metodologia de pesquisa em Direito. 


\section{ABSTRACT}

The epistemological proposals of the feminist and gender studies, think a new perspective for the studies of the sciences, when criticizing the supposed neutrality, universality and objectivity of the traditional Science. The law as a technology aimed at regulating social relations is not neutral or impartiai, because from the lens of gender studies we can perceive a morality of gender that values and positions men and women differently in society.

\section{KEYWORDS}

Gender and Law; Gender and Feminist studies, Law research methodology.

\section{RESUMEN}

Las propuestas epistemológicas de los estudios feministas y de género, piensan una nueva perspectiva para los estudios de las ciencias, al criticar la supuesta neutralidad, universalidad y objetividad de la ciencia tradicional. El derecho como una tecnología que pretende regir las relaciones sociales no es neutral o imparcial a partir de las lentes de los estudios de género podemos percibir una moral de género que valora y posiciona diferentemente a hombres y mujeres en la sociedad.

\section{PALABRAS CLAVE}

Género y Derecho; Estudios de Género y Feministas. metodología de investigación en Derecho. 


\section{INTRODUÇ̧̃̃o}

É a partir de minha própria trajetória como pesquisadora, que neste artigo proponho um debate entre os estudos de gênero e feminista e a ciência jurídica. A ciência jurídica se enquadra como uma ciência que se entende neutra e parcial, mas não o é. É a partir das lentes dos estudos de gênero que podemos perceber uma moral generificada que valora e posiciona diferentemente homens e mulheres na sociedade.

Para as epistemologias feministas e de gênero, as corporalidades, as emoções, as subjetividades constituem as demandas e são levadas em consideração por aquele/as que as aplicam às leis e julgam os casos concretos, ou seja, ambos são pessoas igualmente nutridas por suas subjetividades. Sendo assim, é possível concluir que não há neutralidade nos objetos pesquisados, naqueles que julgam ou legislam e ainda e nos/nas pesquisadoras do campo do direito. Apesar de pouco receptivos para dialogarem com outras áreas científicas que já estão atentas para a subjetividade da pesquisa, como as ciências humanas, os pesquisadores do direito acreditam na imparcialidade da produção de sua ciência.

Outra questão pouco aprofundada no direito é a discussão a partir de dados empíricos, pois geralmente as pesquisas se baseiam somente em aportes teóricos, o que vem se modificando mais recentemente. Alguns campos do direito, como é o caso do direito de família, tem fomentado o debate com outras áreas do saber, atentos para um debate interdisciplinar. Não por acaso é considerada a área mais humana do direito, como exemplo a utilização do conhecimento teórico da psicologia, do serviço social e as técnicas como a mediação tem sido cada vez mais utilizados para a resolução dos conflitos familiares e evitar processos que se arrastam por muitos anos na Justiça.

O Direito pretende ser uma ciência pura, marcada pela neutralidade de seus pesquisadores/as. Marcos Nobre (2005) afirma que há este isolamento do direito em relação a outras áreas científicas e uma confusão entre a prática profissional e a pesquisa acadêmica, sobretudo em relação a atividade de juízes/as e advogados/as que não podem ser tomadas como a própria ciência jurídica. Dessa forma, este autor ressalta que a produção do conhecimento em direito não prioriza a pesquisa empírica, o que faz com que permaneçam os distanciamentos entre o direito e a realidade.

A relação entre a ciência jurídica e o campo dos estudos de gênero e feministas tem crescido no Brasil, o que pode ser identificado a partir do número de teses e dissertações na área (NICHNIG, 2013; MACHADO,2013; OLIVEIRA, 2009), a criação de uma revista especializada ${ }^{2}$ e o surgimento de disciplinas específicas em cursos de graduação em Direito, em instituições como a Universidade Federal de Santa Catarina e na Universidade Federal da Bahia, apenas como exemplo.

Apesar dessas iniciativas, é possível afirmar que o debate dos estudos de gênero, atrelado ao campo jurídico, ainda se faz pouco presente. Se faz necessária a discussão em torno da não neutralidade das decisões, das mais diferentes áreas jurídicas realizadas por operadores/as do direito; das subjetividades dos julgadores/as quando se defrontam com o desempenho de papéis de gênero, como os trânsitos de homens e mulheres no espaço público; as práticas sexuais permitidas e proibidas para

2 Revista Gênero e Direito, publicada pela da Universidade Federal da Paraíba - UFPB. Disponível em: http://periodicos.ufpb. br/index.php/ged/index. Acesso em: 7 dez. 2017. 
homens e mulheres, a reiteração dos cuidados da família e dos filhos pelas mulheres, entre outras questões. Também é possível perceber a subjetividade dos julgadores em promulgar, aplicar e implementar leis que abordem as questões de gênero carregadas de subjetividades e não neutralidade, sendo que o Judiciário é marcado por uma presença de homens, brancos e heterossexuais.

Existe uma pretensa imparcialidade e neutralidade da ciência jurídica que as lentes dos estudos feministas e de gênero precisam debater, principalmente em relação aos julgamentos proferidos pelo Judiciário Brasileiro, seletivo e misógino. Se o conceito de gênero pode ser pensando "como produto e processo de um certo número de tecnologias sociais e aparatos biomédicos" (DE LAURETIS, 1994, p. 208), estou pensando o direito como uma das principais tecnologias sociais que interpelam as relações de gênero, determinam comportamentos e posicionamentos sociais, definindo quais práticas são permitidas e quais são proibidas na sociedade.

Como afirma Isadora Vier Machado (2013, p. 28), os Estudos de Gênero “permitirem um diálogo cruzado com outras áreas do conhecimento, parecem ser o espaço adequado para que se coloque em questão o modelo cartesiano e engendrado de ciência que também contamina a produção científica do Direito" e, portanto, nos ajudam a dialogar com a ciência jurídica. Além de ofuscar a suposta neutralidade do Direito, ao utilizar o gênero e as teorias feministas como categorias de análise, podemos pensar:

Instrumentada por um olhar desconstrucionista de gênero, tem avançado da mera denúncia da exclusão e invisibilidade das mulheres no mundo da ciência para o questionamento dos próprios pressupostos básicos da Ciência Moderna, virando-a de cabeça para baixo ao revelar que ela não é nem nunca foi 'neutra'. (SARDENBERG, 2007, p. 1).

Além de usar os estudos de gênero para literalmente por "de cabeça para baixo" o direito, os questionamentos propostos pelas interseccionalidades e as transversalidades de raça, etnia, geração, orientação sexual, deficiência entre outras, são categorias utilizadas como marcadores sociais da diferença para pensar esta suposta neutralidade (CRENSHAW, 2002; RIOS, 2007).

Os estudos sobre sexualidades, gênero e feminismos nos permitem analisar questões que são cruciais para o direito. As teorias feministas, por exemplo, são importantes para entender que os chamados direitos sexuais estão ligados aos de direitos reprodutivos (SANTIN, 2005) e estes ramos foram introduzidos como pauta de reivindicação por meio dos movimentos feministas.

Dessa forma, entendo o gênero como uma categoria teórica central para pensarmos as questões jurídicas, pois um estado democrático de direito pautado pela democracia, o acesso à justiça e às políticas públicas deve ser acessível a todas as pessoas. Entretanto sabemos que existem desigualdades, de classe, de raça, de gênero, sexualidades, deficiências, que faz com que pessoas tenham ou não acesso aos direitos mínimos garantidos a todos os cidadãos e cidadãs brasileiros. Assim, por exemplo, ao discutirmos o acesso ou não aos direitos e garantias fundamentais no Brasil as teorias de gênero são úteis para dar luz ao debate e demonstrar como as desigualdades e as hierarquias se operam no social, marcados pelo gênero, acarretando diferenças no acesso à justiça, na forma e no tempo dos julgamentos, bem como no acesso as políticas públicas, por exemplo. 
O debate de gênero, em sua conotação política, foi utilizado a partir da segunda metade dos anos 1980 com a "colaboração de algumas teóricas do feminismo, que percebiam a vulnerabilidade dos termos mulher ou mulheres, ao trazerem em seu bojo uma força de legitimação apoiada no corpo biológico desses sujeitos" (PEDRO; VEIGA, 2015). Se o gênero pode ser entendido como categoria relacional e construção histórico-cultural, que dá significado às relações de poder (SCOTT, 1990; NICHOLSON, 2009), também é possível fazer uma discussão sobre as produções e práticas jurídicas fora dos locais centrais. Como sugere Claudia de Lima Costa (1998), houve uma recriação do sujeito e do conceito mulher, sob uma perspectiva política com base nas reivindicações do feminismo como movimento social.

As críticas produzidas pelas feministas decoloniais também nos ajudam a pensar nas perspectivas do sul global e mais propriamente da América Latina marcadas por opressões vividas por mulheres dos países colonizados, marcadas por sua raça, etnia, orientação sexual (MIÑOSO, 2014). Joana Maria Pedro e Ana Maria Veiga também propõem pensar nos debates produzidos na “periferia' estava inserida nas questões que moviam os grandes centros e que ganhariam maior evidência anos depois" (PEDRO; VEIGA, 2015). Além da perspectiva relacional do gênero, estou, também, pensando a categoria como uma prática discursiva e performativa que conforma subjetividades no contexto das relações sociais, políticas e culturais (BUTLER, 2003).

O direito compreendido como uma ciência social ou jurídica, tem como objetivo principal regular as relações em sociedade. Já que sabemos que as relações em sociedade não são iguais, ou seja, são marcadas por desigualdades e discriminações, por que os estudos de gênero ainda não estão inseridos como objeto de análise para o Direito? Essa é uma pergunta importante porque este debate não é considerado pelos teóricos e juristas, já que insistem que a Justiça e as leis são aplicadas igualmente para o "sujeito de direito" dito universal, não reconhecendo as marcações de gênero, geração, deficiências, raça, etnia, sexualidade entre outras. Para o direito o sujeito é neutro, que terá a aplicação da lei mesma forma, independente das marcações sociais. Entretanto, como já denunciam os movimentos feministas, não há neutralidade no Direito. Nas palavras de Daniel Borrilo “El Derecho es denunciado por el feminismo como un instituto masculino y para democratizarlo bartaría pues feminizarlo (BORILLO, 2011, p. 28)3.

Régine Dhoquois, ao falar das interlocuções entre as pesquisas feministas e o direito na França, aponta que "Le droit est un système clos qui a son langage, ses méthodes, ses concepts effectivement forgés par des hommes et à la différence d'autres disciplines des hommes de pouvoir (DHOQUOIS, 2001) $)^{4}$. Anne Marie Goetz (2008) afirma que a luta feminista pela igualdade de gênero na justiça também é demonstrada pela grande contradição que é a divisão entre público e privado, pois se na esfera pública alcançamos parte das demandas por igualdade, não há grandes avanços na esfera do privado. A autora propõe romper a divisão entre público e privado:

30 direito é denunciado pelo feminismo como um instituto masculino e bastaria democratizar para feminizá-lo (Tradução nossa). 40 direito é um sistema fechado que tem sua linguagem, seus métodos, seus conceitos efetivamente forjados por homens e, diferentemente de outras disciplinas, homens de poder. 
La falta de conexión entre lo que se ha alcanzado a los niveles público y privado ilustra una condición esencial que hace que éstos no estén presentes en aquellos esfuerzos prácticos que buscan promover la justicia de género y esto significa que deben romper la división que existe entre lo público y lo privado. (GOETZ, 2008, p. 41. Tradução nossa).

Como veremos no tópico a seguir, em relação a legislação sobre o aborto no Brasil, não podemos deixar de marcar que vivemos em um país que atravessou o processo de colonização e permaneceu por séculos sob o jugo do colonizador, utilizando sua legislação, que não condizia com sua realidade e trazia em seu bojo uma visão dominantemente masculina. Logo são as feministas decoloniais que denunciam a presença de "un derecho aún más arcaico y patriarcal, implícito en los múltiples productos normativos del catolicismo colonial” (CUSICANQUI, 2014, p. 122).

\section{IGUALDADE X DESIGUALDADE NA JUSTIÇA: QUE LEIS TEMOS E QUAIS LEIS QUEREMOS? QUEM FORMULA AS LEIS NO BRASIL?}

As leis brasileiras, são produzidas e propostas (na sua maioria) pelo poder legislativo, que se constitui como um poder disciplinar, regendo os relacionamentos e até impondo limites às (diversas) formas de se relacionar, das vivências conjugais e familiares. Judith Butler, ao ler Michel Foucault, analisa os sistemas jurídicos e as leis como reguladores dos sujeitos, "em termos puramente negativos - isto é, por meio de limitação, proibição, regulamentação, controle e mesmo "proteção" dos indivíduos relacionados àquela estrutura política, mediante uma ação contingente e retratável de escolha" (BUTLER, 2003, p. 18).

Se pensarmos no contexto brasileiro, as leis desde o período colonial visavam regular e vigiar as relações pessoais, sendo que o direito surge a serviço das oligarquias e de uma sociedade patriarcal e católica, em que os direitos das mulheres não eram contemplados. Apesar de que no século XX tivemos a promulgação de importantes leis que modificaram as relações pessoais e familiares no Brasil, é somente no chamado período de redemocratização que reivindicações próprias de grupos sociais se fizeram ouvidas durante a Constituinte.

Após o período de ditadura militar, é que podemos observar a emergência das lutas e agendas específicas de grupos identitários, como uma expressão de forças de pessoas silenciadas naquele período violento e obscuro da História do Brasil. Mulheres, negros/as, indígenas, trabalhadores/as, pessoas com deficiências entre outros reivindicam seus direitos e suas legislações específicas, sendo este período marcado por importante participação popular por meio da presença dos movimentos sociais.

É somente com a Constituição Federal de 1988, considerada a mais liberal e democrática dos textos constitucionais, também como constituição cidadã, que o sujeito de direito está no centro da legislação. Assim, a legislação brasileira que tinha como principal objetivo proteger a propriedade privada, passa a proteger e conceder direitos para os cidadãos e cidadãs, baseados nos princípios constitucionais da dignidade da pessoa humana, da igualdade e da não discriminação. Assim, após 
o longo e árduo período de Ditadura Militar e com o início da abertura política é que novos sujeitos puderam impor suas reivindicações, articulados em movimentos sociais. Não é possível esquecer que o legislativo é um espaço masculino, geralmente formado por homens, brancos e heterossexuais que legislam para todos e todas.

0 resultado de correlações de forças, de lutas sociais e pela intensa participação política é que direitos específicos foram conquistados, em especial destaco a conquista da igualdade formal entre homens e mulheres. Assim, determina a Carta magna "homens e mulheres são iguais perante a lei, nos termos da Constituição”. São esses novos sujeitos políticos e sujeitos de direito que adentram a cena pública no Brasil e trazem suas reivindicações específicas. É nessa esteira que temas como o Meio Ambiente e a Educação ganham destaque.

Em relação às legislações que tocam as relações de gênero destaco as mudanças sociais trazidas por duas legislações na área do direito civil, anteriores a Constituição de 1988: o Estatuto da mulher casada, de 1962, que trouxe inúmeras modificações como incluir as mulheres como civilmente capazes, retirando as mulheres da condição de relativamente capazes; e a lei do divórcio, de 1977, que permitiu que casais que se separem e divorciem possam ter direito de constituir novas famílias, não sendo mais as novas famílias e seus filhos considerados como ilegítimas e ilegítimos.

Mas mesmo que sejam considerados iguais perante a Constituição Federal, ainda muito há que ser feito. 0 que quero dizer é que atingida a igualdade formal, há uma desigualdade que atinge na realidade homens e mulheres. Um ponto que precisa ser abordado é a questão da desigual atribuição de atividades desempenhadas pelos casais, seja no cuidado com os filhos, seja na realização dos trabalhos domésticos. Se tivermos uma legislação que determina a igualdade entre homens e mulheres, ainda não há, no campo da cultura, uma igual divisão de tarefas domésticas por exemplo, principalmente quando tratamos da esfera dos cuidados. Em vídeo específico ${ }^{5}$, Rita Segato esclarece que há uma "privatização do espaço doméstico", para ela é muito difícil “entrar a luz do direito moderno" em relação às questões da vida íntima, por exemplo no que se refere a divisão do trabalho doméstico.

Além da igualdade entre homens e mulheres, a Constituição Federal incluiu o princípio da não discriminação por sexo, sendo este uma importante conquista. A inclusão daquilo que chamamos como direitos sexuais e pela diversidade e igualdade sexual está profundamente ligada às trajetórias destas lutas pelos direitos humanos das mulheres e aos processos de retomada da democracia. Como destaquei poderíamos abordar a não neutralidade do direito sob diferentes aspectos, mas irei me ater neste artigo a temática do aborto.

\section{PENSANDO SOBRE UMA LEI ESPECÍFICA: A QUESTÃO DO ABORTO}

Se por um lado no Brasil temos legislações que visam proteger as mulheres em situação de violências, principalmente porque estamos tratando de mulheres que estão em seu lugar destinado, o espaço privado e sob a ideia do "lar doce lar" despedaçado. O Estado deve intervir para proteger as

5 Disponível em: https://www.youtube.com/watch?v=wdc0YCwW3Yk. Acesso em: 2 jun. 2018. 
vítimas, em outras questões como o aborto são estas as únicas penalizadas pelo ato. Ou seja, quando consideradas supostas autoras de crimes são penalizadas pelo Estado que as protege. Estou falando do crime de aborto, que pune somente quem pratica e quem ajuda a praticar.

No Brasil, o aborto "provocado pela gestante ou com seu consentimento" é crime com pena prevista de detenção de dois a seis anos, previsto nos artigos 124 a 128 do Código Penal Brasileiro. Entretanto, está previsto o aborto necessário em "que não há outro meio de salvar a vida da gestante" e também o "aborto no caso de gravidez resultante de estupro". Nestes dois casos o aborto não é criminalizado. Após decisão histórica do Supremo Tribunal Federal em 2012, na Arguição de Descumprimento de Preceito Fundamental de número 54 foi declarado inconstitucionais os artigos do Código Penal que punem pelo crime de aborto mulheres que praticam a intervenção em casos de fetos anencéfalos ${ }^{6}$.

Quem pratica o aborto são as mulheres, na sua maioria pobres e negras, criminalizadas pela lei penal. Não são os homens que sofrem os rigores da lei penal. A legislação entende que não existe autonomia sobre o próprio corpo das mulheres, quando elas carregam fetos indesejados, devendo cuidá-los e protegê-los até o seu nascimento com vida. Os fetos, chamados pela lei como nascituros, são protegidos por leis como o Estatuto do Nascituro ${ }^{7}$, que retira direitos e a autonomia das mulheres sobre seus próprios corpos.

A criminalização do aborto afeta o exercício da sexualidade feminina e a própria vida das mulheres, pois estas sabem como fazê-lo e o fazem, apesar da proibição legal (PEDRO, 2003). Mas é importante lembrar: somente as mulheres são criminalizadas, não seus maridos ou companheiros. São suas vidas que não importam é que estão em jogo.

Atualmente, a maioria das leis em tramitação que abordam a temática são no sentido de retroceder direitos historicamente conquistados, como por exemplo o já citado Estatuto do Nascituro, que obrigaria a mulher vítima de estupro gerar a vida fruto de uma violência e com a obrigação de futuramente ter que conviver com o seu estuprador, que transformaria em pai do seu filho/a. 0 estado concederia uma bolsa estupro para essa mulher sustentar seu filho.

No Brasil a discussão veio recentemente à tona pelo julgamento da Arguição de Descumprimento de Preceito Fundamental 442 -ADPF 442 durante a audiência pública realizada em agosto de $2018^{8}$. Proposta pelo Instituto de Bioética (ANIS) e o Partido Socialismo e Liberdade (PSOL), em 8 de março de 2017, a ação tem como objetivo discutir o descumprimento da Constituição pelos artigos 124 e 126 do Código Penal, que tratam da criminalização do aborto. A ação visa a descriminalização da prática e a exclusão do âmbito de incidência dos dois artigos a interrupção da gestação induzida e voluntária realizada nas primeiras 12 semanas de gestação.

Nos dias 3 e 6 de agosto de 2018 a relatora, Ministra Rosa Weber do Supremo Tribunal Federal (STF), ouviu inúmeros depoimentos de especialistas a favor e contra o aborto na tribuna da mais alta corte do judiciário brasileiro. Naquela oportunidade os depoimentos de Debora Diniz, representante

6 Para a decisão na íntegra ver: http://portal.stf.jus.br/processos/downloadPeca.asp?id=136389880\&ext=.pdf. Acesso em: 1 fev. 2019. 7 PL 478/2007. Disponível em: http://www.camara.gov.br. Acesso em:15 ago. 2018.

8Arguição de Descumprimento de Preceito Fundamenta 442. Número único 0002062-31.2017.1.00.0000, Origem: Distrito Federal, Relatora: Ministra Rosa Weber. Disponível em: www.stf.jus.br. Acesso em: 10 ago. 2018. 
do ANIS, a qual apresentou na tribuna o perfil das mulheres que fazem aborto no Brasil ${ }^{9}$, sendo que "há uma distribuição desigual do risco com a maior concentração entre as mulheres mais jovens, mais pobres, nortistas e nordestinas, negras e indígenas" ${ }^{10}$.

As participações na Tribuna a favor do aborto trouxeram dados de como o aborto no Brasil deve ser tratado como um caso de saúde de pública, por ceifar a vida sobretudo de mulheres pobres e negras. O julgamento do referido processo ficou adiado e sua decisão com certeza trará reações fervorosas de ambos os lados principalmente a partir da eleição do novo presidente da República e da nomeação da Ministra da Mulher, da Família e dos Direitos Humanos, Senhora Damares Alves, a qual sugere que o modelo de família seja representado pela mãe cuidadora dos filhos que não trabalha fora e, como pastora evangélica fervorosa, é contrária ao aborto em qualquer situação ${ }^{11}$.

É importante lembrar em 2018 o fenômeno “marea verde", iniciado em 2005 na Argentina, invade as ruas com reivindicações feministas em favor do aborto legal, seguro e gratuito no país. A campanha feminista levou às manifestações mais de dois milhões de pessoas com seus lenços verdes em favor da legalização da prática, segundo nos conta Maria Alicia, articulista da Campanha Nacional por Aborto Legal, Seguro e Gratuito na Argentina ${ }^{12}$. Aprovada na câmara, posteriormente foi proibido no Senado argentino, mas Maria Alicia aponta para o impacto positivo da campanha da Argentina em outros países da América Latina, que também se articulam em razão da legalização do aborto.

\section{CONSIDERAÇÕES FINAIS}

O que concluo, a partir destas breves discussões, é que o Estado visa proteger famílias e mulheres no papel de mães e cuidadoras. Não são as mulheres como sujeitas autônomas e com o direito ao próprio corpo que o Estado visa proteger. E essa moral é generificada e está imbuída de valores que posicionam diferentemente homens e mulheres socialmente. Rita Segato fala de uma agenda política global marcada por uma moral de gênero, patriarcal, para a qual a posição das mulheres é de subserviência, vinculada exclusivamente a família.

Também em relação aos julgamentos em temas penais é possível perceber diferenças nas formas de julgar e nas práticas jurídicas e policiais. Ao tempo em que existe um sistema de proteção para as mulheres vítimas de violências, com a aplicação da Lei Maria da Penha, por exemplo, e que uma modificação na legislação penal, com a descriminalização das ofensas contra a moral sexual (como a retirada dos crimes de adultério e sedução, por exemplo) há uma forma diferente de julgar homens

9 Disponível em: http://www.stf.jus.br/portal/cms/verNoticiaDetalhe.asp?idConteudo=385663. Acesso em: 10 ago. 2018. 10 Disponível em: http://www.stf.jus.br/portal/cms/verNoticiaDetalhe.asp?idConteudo=385663. Acesso em: 10 ago. 2018. 11 Disponível em: https://www.brasil247.com/pt/247/brasil/381902/Em-v\%C3\%ADdeo-contra-o-aborto-Damares-aparece-com-as-m\%C3\%A3os-'sujas-de-sangue'.htm. Acesso em: 15 ago. 2018.

12 Maria Alicia, articulista da Campanha Nacional por Aborto Legal, Seguro e Gratuito. Portal Catarinas, 16 ago. 2018. Disponível em: https://www.youtube.com/watch?v=Q-NIT2uxDHg. Acesso em: 16 ago. 2018. 
e mulheres que são autores/vítimas dos citados crimes. Muitas mulheres quando são vítimas são os seus comportamentos que são julgados e não os comportamentos dos autores de violências.

Ainda, se observa que as mulheres são protegidas pela legislação quando se comportam como é esperado, por uma moral conservadora; quando fogem deste padrão não são merecedoras de proteção legal. 0 que quero chamar atenção que a lei é para todas e não apenas para as mulheres que se comportam conforme valores e papéis morais e sociais esperados. Pode parecer que essa é uma constatação aceitável para os julgamentos do século passado, como os comportamentos analisados por historiadoras como Marta de Abreu (1989), Joana Maria Pedro e Cristina Scheibe Wolff (1999), mas isso se aplica em julgamentos atualmente. Nos julgamentos de casos de violência sexual, como o estupro, que o comportamento da vítima é exposto como para corroborar o fato de que esta "pediu" para ser violentada.

As mulheres transexuais, as travestis, as aborteiras, as putas, as mães “desnaturadas" merecem proteção legal? Para muitos julgadores não, mesmo que a lei diga que todas as mulheres devam ser igualmente protegidas pela lei, sem qualquer distinção. Para as mães, somente devem ser protegidas quando estiverem exercendo os papéis “naturais” de amorosas e cuidadoras. Já, as mães "desnaturadas” estas não são dignas de proteção, como as mães que abandonam crianças, as aborteiras, as infanticidas, entre outras consideradas aberrações, pois fogem do padrão da mãe zelosa e cuidadosa.

O que quero dizer com isso que há uma proteção legal para as mulheres que estejam nos papéis previamente concebidos para elas socialmente; para a mulher que busca autonomia há muita misoginia e discriminação. De certa forma, o sistema de proteção jurídica vigente visa a proteção da família e não da mulher autônoma, o que se traduz numa ideia de familismo na legislação (NICHNIG, 2013)

A professora Salete Maria da Silva, da Universidade Federal da Bahia, traz à tona uma importante discussão sobre o feminismo jurídico, sustentando que ele pode modificar essa realidade. Segundo a autora, trata-se de um debate teórico apurado realizado pelas teorias feministas em relação ao direito, mas também de práticas jurídicas contestatórias. Para a Salete Maria, o feminismo jurídico "corresponde a um conjunto de críticas, teorizações, proposições metodológicas e atividades práticas desenvolvidas por juristas feministas em face do fenômeno jurídico, dentro ou fora do sistema de justiça" (SILVA, 2018, p. 90).

Ao observarmos o uso do gênero, em julgamentos concretos onde se dá a aplicação da lei, vemos que o direito é um fenômeno gendrado, isto é, julga diferentemente homens e mulheres. Urge, portanto, lutarmos por igualdade não só no plano formal, mas colocarmos em prática também o feminismo no campo jurídico.

\section{REFERÊNCIAS}

BUTLER, Judith R. Problemas de gênero: feminismo e subversão da identidade. Rio de Janeiro: Civilização Brasileira, 2003. 
CRENSHAW, Kimberlé. Documento para o encontro de especialistas em aspectos da discriminação racial relativos ao gênero. Estudos Feministas, Florianópolis, v. 10, n. 1, p. 171-188, jan. 2002.

COSTA, Claudia de Lima Costa. 0 tráfico de gênero. Cadernos Pagu, n. 11, p. 127-140, 1998.

CUSICANQUI, Silvia Rivera. La nócio de derecho o la paradoja de la modernidad poscolonial: indígenas y mujeres en Bolivia. In: MIÑOSO, Yuderkys Espinosa. et al. Tejiendo de otro modo: feminismo, epistemología y apuestas descoloniales em AbyaYala. Editoria Universidad del Cauca, 2014. p. 121-134.

DINIZ, Debora; VELEZ, Ana Cristina Gonzalez. Aborto na suprema corte: o caso da anencefalia no Brasil. Estudos Feministas, v. 16, n. 2, p. 647-652, 2008.

DHOQUOIS, Régine. La recherche féministe à l'université dans le domaine du droit.Une absence en forme de désertion. In: GARCÍA, Gonzáles. Les Cahiers du CEDREF, Paris, n. 10, 2001. Disponível em: http://cedref.revues.org/278. Acesso em: 5 jun. 2010

DE LAURETIS, Teresa. A tecnologia do gênero. In: HOLLANDA, Heloisa Buarque de (org.). Tendências e impasses: o feminismo como crítica da cultura. Rio de Janeiro: Rocco, p. 206-242, 1994.

ELIAS, Maria Lígia Granado; MACHADO, Isadora Vier. A construção social da liberdade e a Lei Maria da Penha. Revista Sul Americana de Ciência Política, Pelotas, Rio Grande do Sul, v. 3, n. 1, p. 88-109, 2015.

ESTEVES, Martha de Abreu. Meninas perdidas: os populares e o cotidiano do amor no Rio de Janeiro da belle époque. Rio de Janeiro: Paz e Terra, 1989.

GOETZ, Anne Marie. Justicia de género, ciudadanía y derechos. Conceptos fundamentales, debates centrales y nuevas direcciones para la investigación. In:

MUKHOPADHYAY, Maitrayee; NAVSHARAN, Singh. Justicia de género, ciudadanía y desarrollo. Colombia: Mayol Ediciones, 2008. p. 13-45.

HARARI, Sofia; PASTORINO, Gabriela L. Acerca del género y el derecho. In: BIRGIN, Haydée (comp.). El derecho en el género y el género en el derecho. Buenos Aires: Biblios, 2000.

MACHADO, Isadora Vier. Da dor no corpo à dor na alma: uma leitura do conceito de Violência Psicológica da Lei Maria da Penha. Tese (Doutorado) - Programa Doutorado Interdisciplinar em Ciências Humanas, Centro de Filosofia e Ciências Humanas, Universidade Federal de Santa Catarina, Florianópolis, 2013.

NICHNIG, Claudia Regina. Para ser digno há de ser livre: reconhecimento jurídico da conjugalidade entre pessoas do mesmo sexo no Brasil. Tese (Doutorado em Ciências Humanas) - Programa de 
Pós-Graduação Interdisciplinar em Ciências Humanas, Universidade Federal de Santa Catarina, Florianópolis, 2013.

NICHNIG, Claudia Regina. Le Collectif Onze: Au tribunal des couples. Enquête sur des affaires familiales. Nouvelles Questions Féministes, v. 35, n. 2, p. 133-136, 2016.

NICHOLSON, Linda. Interpretando o gênero. Estudos Feministas, v. 8, n. 2, p. 9-41, Florianópolis: UFSC, 2009.

NOBRE. Marcos. 0 que é pesquisa em direito? São Paulo: Quartier Latin, 2005.

OLIVEIRA, Rosa Maria Rodrigues de. Isto é contra a natureza? Decisões e discursos sobre conjugalidades homoeróticas em Tribunais Brasileiros. Tese (Doutorado) - Programa do Doutorado Interdisciplinar em Ciências Humanas, Centro de Filosofia e Ciências Humanas, Universidade Federal de Santa Catarina, Florianópolis, 2009.

OLIVEIRA, Melissa Barbieiri de. Transtornando o campo jurídico: uma análise da construção da categoria transexual na doutrina jurídica brasileira e seus efeitos no reconhecimento das pessoas trans como sujeito de direitos. Tese (Doutorado) - Programa do Doutorado Interdisciplinar em Ciências Humanas, Centro de Filosofia e Ciências Humanas, Universidade Federal de Santa Catarina, Florianópolis, 2017.

PEDRO, Joana Maria. Mulheres honestas e mulheres faladas: uma questão de classe. Florianópolis: UFSC, 1998.

PEDRO, Joana Maria (org.). Práticas proibidas: práticas costumeiras de aborto e infanticídio no século XX. Florianópolis: Cidade Futura, 2003.

PEDRO, Joana Maria; VEIGA, Ana Maria. Gênero. In: COLLING, Ana Maria; TEDESCHI, Losandro (org.). Dicionário Crítico de Gênero. Dourados, MS: Ed. UFGD, 2015. p. 304-307.

RIOS, Roger Raupp. Por uma perspectiva feminista no debate jurídico: Anotações a partir do julgamento do Habeas Corpus 81.288-1-SC pelo Supremo Tribunal Federal. Cadernos Themis, Porto Alegre, ano III, n. 3. 2002, p. 165-179.

RIOS, Roger Raupp. (org.). Em defesa dos direitos sexuais. Porto Alegre: Advogado, 2007.

SARDENBERG, Cecilia. Da crítica feminista à ciência a uma ciência feminista? Labrys. Estudos Feministas, v. 11, 2007. 
SILVA, Salete Maria da; WRIGHT, Sonia Jay. Uma reflexão feminista sobre o conceito de Justiça de Gênero. Teorias da Justiça, da Decisão e da Argumentação Jurídica, v. 2, n. 1, p. 216, 2016.

SILVA, Salete Maria da. Feminismo jurídico: uma introdução. Cadernos de Gênero e Diversidade, v. 4, n. 1, p. 83-102, jan./mar. 2018.

SANTIN, Myrian Aldana Vargas. A incidência da Igreja Católica na tramitação do PL 20/91 - aborto legal e PL 1151/95 - união civil entre pessoas do mesmo sexo. Tese (Doutorado) - Programa de Pós-Graduação Interdisciplinar em Ciências Humanas, Centro de Filosofia e Ciências Humanas, Universidade Federal de Santa Catarina, 2005.

SCOTT, Joan. Gênero: uma categoria útil de análise histórica. Educação e Realidade, Porto Alegre, v. 16, n. 2, jul./dez. 1990.

SEGATO, Rita. El patriarcado es un tema central para mantener el edificio de los poderosos.

Disponível em: https://www.youtube.com/watch?v=wdcOYCwW3Yk. Acesso em: 2 jun. 2018.

SMART, Carol. Teoria feminista y el discurso jurídico. In BIRGIN, Haydée (comp.). El derecho en el género y el género en el derecho. Buenos Aires: ed. Biblos, 2000. p. 31-71.

WOLFF, Cristina Scheibe. Mulheres da floresta: uma história. São Paulo: Hucitec, 1999. 9 
1 Professora visitante do Programa de Pós-Graduação em História, da Universidade Federal da Grande Dourados UFGD; Pós-doutora em História, pela Universidade Federal de Santa Catarina - UFSC e em Antropologia Social pela École des hautes études en sciences sociales - EHSS, em Toulouse/França. Este texto foi inspirado na tese de doutorado intitulada "Para ser digno há de ser livre: reconhecimento jurídico da conjugalidade entre pessoas do mesmo sexo no Brasil", defendida em 2013, no Programa Doutorado Interdisciplinar em Ciência Humanas da UFSC, na área de Estudos de Gênero. E-mail: claudianichnig@gmail.com

\section{(). (1) (2)}

Este artigo é licenciado na modalidade acesso abertosob a Atribuição-Compartilhalgual CC BY-SA

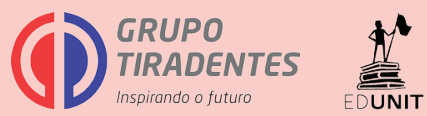

